\title{
Dual Transoral Endoscopic Resection of a Symptomatic Giant Brunneroma
}

\author{
M.C. Sulz ${ }^{\mathrm{a}} \quad$ M. Thurnheer ${ }^{\mathrm{b}} \quad$ C. Meyenberger \\ aDepartment of Medicine, Division of Gastroenterology and Hepatology, and \\ ${ }^{b}$ Department of Surgery, Hospital of St. Gallen, St. Gallen, Switzerland
}

\section{Key Words}

Giant brunneroma - Endoscopic resection - Endo-surgery

\begin{abstract}
Brunneroma is a rare, benign, proliferative lesion arising from the Brunner's glands of the duodenum that exceptionally may evolve towards a malignant transformation, usually discovered incidentally at endoscopy. Occasionally, these lesions manifest as a rare cause of duodenal obstruction or upper gastrointestinal bleeding and require resection, usually for tumors larger than $4 \mathrm{~cm}$. The special aspect of our case is the technically difficult but successful dual transoral endoscopic resection of a giant $(6.5 \times 4 \times 2.4 \mathrm{~cm})$ brunneroma with a very thick and long peduncle located extremely close to the pylorus, highlighting the possibilities of endosurgery. Distal stomach resection with Roux-en-Y reconstruction as an alternative would have caused higher morbidity and costs.
\end{abstract}

\section{Introduction}

Brunneroma is a rare, benign, proliferative lesion arising from the Brunner's glands of the duodenum that exceptionally may evolve towards a malignant transformation $[1,2]$, usually discovered incidentally at endoscopy. Occasionally, these lesions manifest as a rare cause of duodenal obstruction or upper gastrointestinal bleeding and require resection, usually for tumors larger than $4 \mathrm{~cm}$. We report a case of a giant brunneroma $(6.5 \times 4 \times 2.4 \mathrm{~cm})$ resected endoscopically with two endoscopes via oral access.

\section{Case Report}

In 2008 a 50-year-old man was admitted with progressive iron deficiency anemia (hemoglobin $66 \mathrm{~g} / \mathrm{l}$, ferritin $9 \mu \mathrm{g} / \mathrm{l})$ and a history of fatigue and melena. Upper endoscopy revealed a large $(6 \times 2 \mathrm{~cm})$ pedunculated polyp in the duodenal bulb, with its basis extremely close to the pylorus, extending to the second/third portion of the duodenum due to a very long peduncle (fig. 1). Several therapeutic 
approaches were considered, of which we decided to perform the third: (a) surgical approach with distal stomach resection and Roux-en-Y reconstruction, (b) laparoscopic-transgastric approach with surgical resection and transoral endoscopic salvage of the polyp, or (c) sole endoscopic resection under general anesthesia and surgical 'standby'.

Right from the start the procedure was performed under general anesthesia in a fully equipped operating room. Pre-interventional single shot antibiotic was not given. Both endoscopists stood on the left side of the patient's head. The patient was in the supine position. The second endoscope was attached to the monitor of the laparoscopic tower which was installed for surgical 'standby'.

After injection of $10 \mathrm{ml}$ epinephrine 1:100,000 we tried to luxate the polyp into the gastric lumen. Useful devices for technical assistance could not be passed through a second transnasally inserted gastroscope. Instead a second gastroscope (Olympus GIF 160) was inserted transorally (ig. 2). Friction between the two endoscopes was reduced properly by the sliding effect of silicone spray. The mobility of each endoscope was limited, however both endoscopists got used to the limitation. No mucosal damage, which could have been caused by the two gastroscopes, was seen in the oral cavity and the esophagus. Finally, after several attempts with different endoscopic devices through both gastroscopes, the polyp could be placed into the gastric lumen with two loops attached to the distal end, allowing to straighten the polyp during polypectomy (fig. 3 ). Resection was performed with a polypectomy snare at the basis of the polyp (Erbe ${ }^{\circledR}$ Endocut Modus). The periinterventional bleeding stopped spontaneously. The transorally saved polyp measured $6.5 \times 4 \times 2.4 \mathrm{~cm}$, its peduncle $5.5 \times 2 \mathrm{~cm}(\underline{\text { fig. }}$ ) $)$. The large resection base appeared endoscopically deep with a high risk of delayed perforation (fig. 5). Unfortunately, endoscopic interventional closure with metal clips was not successful simply because the resection base was too large. Therefore our laparoscopic surgeon (standby) performed a laparoscopy. After laparoscopic mobilisation of the proximal duodenum and the distal antrum, a large transmural duodenal wall defect was seen from the posterior to the ventral wall extremely close to the pylorus. The defect was sutured successfully laparoscopically and checked by gastroscopic inspection and air insufflation. The whole procedure lasted $4 \mathrm{~h}$.

Microscopically, the polyp consisted of closely packed Brunner's gland without signs of malignancy. The patient was discharged after 9 days and was seen in the clinic without any complaints at 2-month follow-up.

\section{Discussion}

Benign tumors of the duodenum are very rare, with an incidence of $0.008 \%$ in a single series of 215,000 autopsies, and those originating from Brunner's glands only account for $11 \%$ of these tumors [3]. In the majority of cases, brunneroma - also known as Brunner's gland adenoma - develops into a polypoid mass, usually pedunculated (88\%), $1-2 \mathrm{~cm}$ of size [4], while few cases reaching several centimetres as 'giant brunneroma' have been reported $[5,6]$. The majority of cases are asymptomatic. The clinical manifestations include pain, gastrointestinal bleeding, and obstructive symptoms [7]. Endoscopy allows direct visualization of the lesion, biopsy to rule out malignancy, and the procedure is a more cost-effective and less invasive treatment option than abdominal surgery $[8,9]$. However, the success depends on the site and size of the brunneroma and the presence of a peduncle. Several cases of successful endoscopic resections have been reported $[6,10]$.

The special aspect of our case is the technically difficult but successfull dual transoral endoscopic resection of a giant $(6.5 \times 4 \times 2.4 \mathrm{~cm})$ brunneroma with a $2 \times 5.5 \mathrm{~cm}$ peduncle extremely close to the pylorus, highlighting the possibilities of endosurgery. Using a second endoscope is not common practice in our department, but in this particular case we prepared a second endoscope beforehand to have technical assistance in case. For security reasons the endoscopic procedure should be performed under general anesthesia in a fully equipped operating room with surgical 'standby'. With regard to interventional mobility one can say that the use of two transorally inserted gastroscopes does limit the mobility of each endoscope. However, the friction between the two endoscopes can be reduced sufficiently by the sliding effect of silicone spray. Both endoscopists need to get 


\begin{tabular}{r|l|l|l} 
Case Reports $/ \mathrm{h}$ & $\begin{array}{l}\text { Case Rep Gastroenterol 2009;3:260-264 } \\
\text { D01: 10.1159/000235236 }\end{array}$ & Published online: August 28, 2009 & $\begin{array}{l}\text { O 2009 S. Karger AG, Basel } \\
\text { ISSN 1662-0631 } \\
\text { Www.karger.com/crg }\end{array}$ \\
\hline
\end{tabular}

used to this limitation. It must be mentioned that the transoral insertion of two gastroscopes can be considered as safe. In our case no mucosal damage was seen in the oral cavity and the esophagus.

As in our case, a large and deep resection base with high risk of delayed perforation shows one of the current technical limits of interventional endoscopy being dependent of laparoscopic suturing. There is a lack of special endoscopic devices. However, there is a fast development in interventional endoscopy/endosurgery looking at the possibilities of NOTES $^{\text {TM }}$ (natural orifice translumenal endoscopic surgery). Even though the assistance of the laparoscopic surgeon with suturing the transmural defect was needed after successful endoscopic resection of the giant brunneroma, distal stomach resection with Roux-en-Y reconstruction as an alternative would have caused higher morbidity and costs.

Fig. 1. Upper endoscopy shows a large $6 \times 2 \mathrm{~cm}$ pedunculated polyp in the duodenal bulb, with its basis extremely close to the pylorus at the posterior wall, extending to the second/third portion of the duodenum due to a very long peduncle.

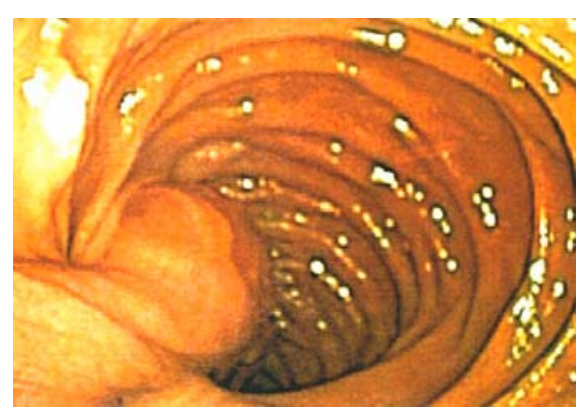

Fig. 2. Two endoscopes (Olympus GIF 1TQ 160 and Olympus GIF 160) are inserted transorally.

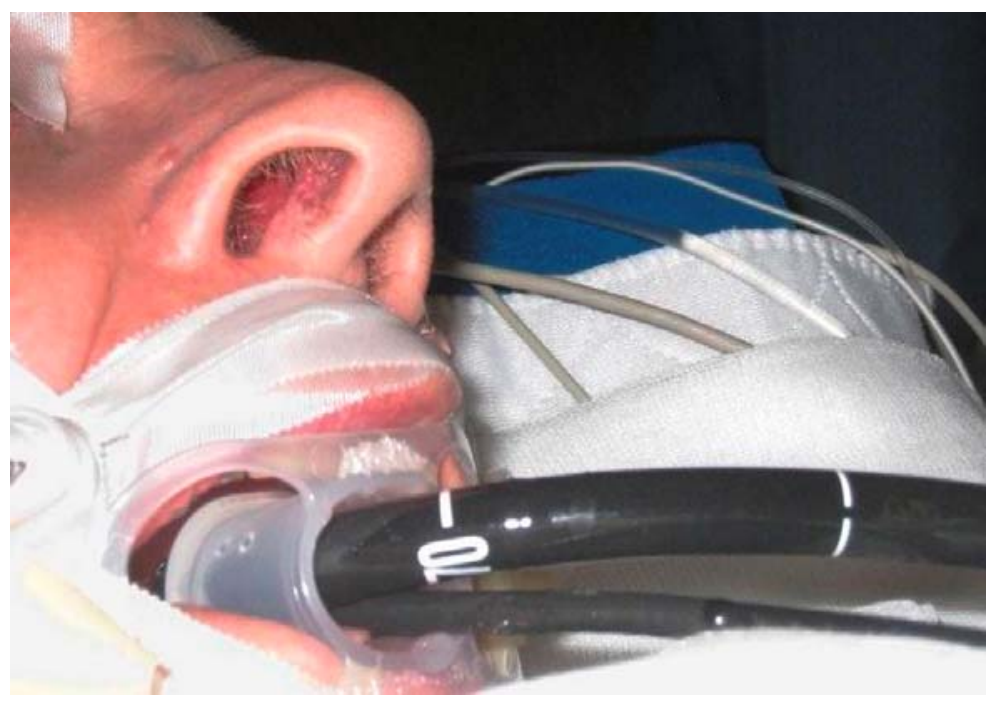




\begin{tabular}{r|l|l|l} 
Case Reports $h$ Case Rep Gastroenterol 2009;3:260-264 & Published online: August 28, 2009 & $\begin{array}{l}\text { O 2009 S. Karger AG, Basel } \\
\text { ISSN 1662-0631 } \\
\text { www.karger.com/crg }\end{array}$ \\
& & & \\
\hline
\end{tabular}

Fig. 3. The polyp is luxated into the gastric lumen by two loops attached to the distal end of the polyp.

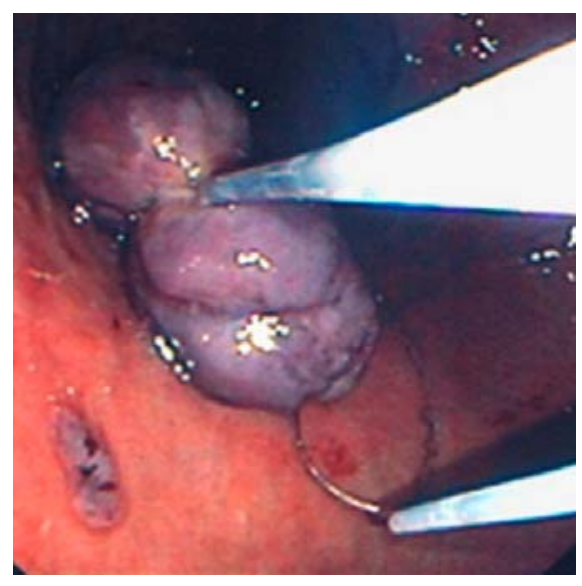

Fig. 4. Successfull dual transoral endoscopic resection of a giant brunneroma with a size of $\overline{6.5 \times 4} \times 2.4 \mathrm{~cm}$ and a very thick $(2 \mathrm{~cm})$ and long $(5.5 \mathrm{~cm})$ peduncle.

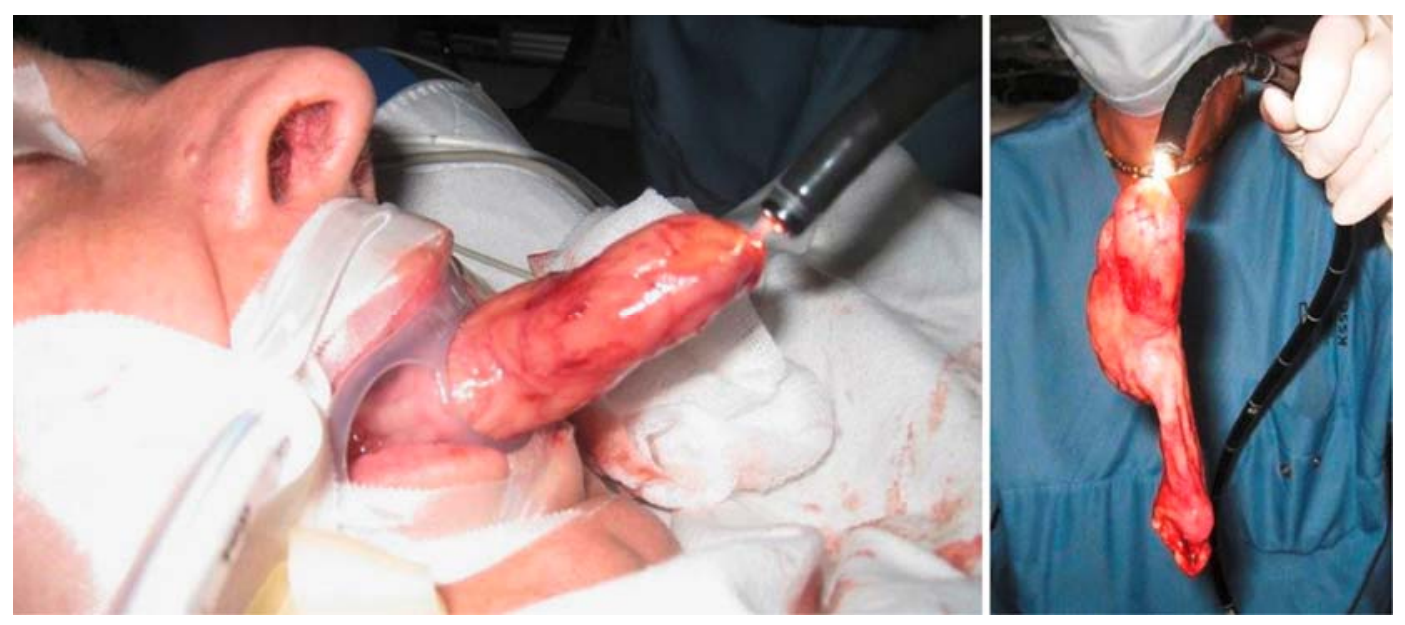

Fig. 5. The large resection base (R) seemed to be deep with a high risk of delayed perforation.

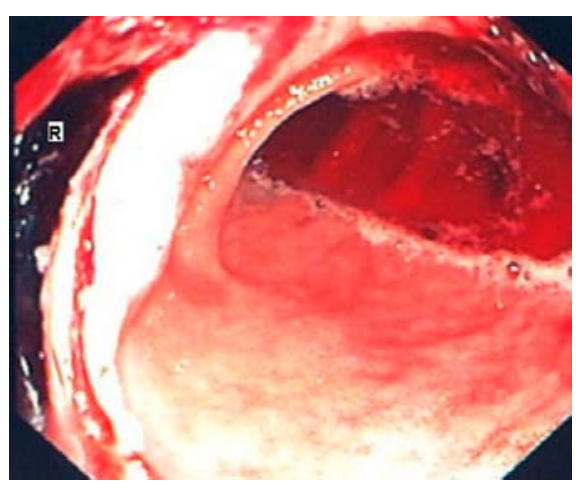




\section{References}

1 Brookes MJ, Manjunatha S, Allen CA, Cox M: Malignant potential in a Brunner's gland hamartoma. Postgrad Med J 2003;79:416-417.

-2 Fujimaki E, Nakamura S, Sugai T, Takeda Y: Brunner's gland adenoma with a focus of p53-positive atypical glands. J Gastroenterol 2000;35:155-158.

-3 Botsford TW, Crowe P, Crocker DW: Tumours of the small intestine. Am J Surg 1962;103:358-362.

-4 Nakanishi T, Takeuchi T, Hara K, Sugimoto A: A great Brunner's gland adenoma of the duodenal bulb. Dig Dis Sci 1984;29:81-85.

5 Rhiner R, Meyenberg A, Aeberhard P, Moschopulos M: Large Brunner's adenoma of the duodenal bulb: a case report. Swiss Surg 1997;3:13-16.

6 Rocco A, Borriello P, Compare D, et al: Large Brunner's gland adenoma: Case report and literature review. World J Gastroenterol 2006;12:1966-1968.

7 Levine JA, Burgart LJ, Batts KP, Wang KK: Brunner's gland hamartomas: clinical presentation and pathological features of 27 cases. Am J Gastroenterol 1995;90:290-294.

$>8$ Park JH, Park CH, Park JH, et al: The safety and usefulness of endoscopic polypectomy for treatment of Brunner's gland adenomas. Korean J Gastroenterol 2004;43:299-303.

-9 Baladas JG, Borody TJ, Smith GS, Dempsey MB, Richardson MA, Falk GL: Laparoscopic excision of a Brunner's gland hamartoma of the duodenum. Surg Endosc 2002;16:1636.

10 Gao YP, Zhu JS, Zheng WJ: Brunner's gland adenoma of duodenum: a case report and literature review. World J Gastroenterol 2004;10:2616-2617. 